\title{
Faith and spirituality as psychological coping mechanism among female aid workers: a qualitative study
}

\author{
Ozgul Ozcan *iD, Mark Hoelterhoff and Eleanor Wylie
}

\begin{abstract}
Despite evidence that faith-based and spiritual coping supports people's mental health, stigmata prevail in the aid sector around the need for psychological support in general and around this coping mechanism in particular. This qualitative research examines female aid workers' experiences and aims to elucidate how this mechanism supports mental health in stressful, conflict, or disaster-affected living and working environments. Inductive thematic analysis of 14 semi-structured interviews reveals three themes around (a) specificities of the aid work context, (b) benefits and gains through this coping mechanism and related processes, and (c) potential downsides. Interview findings suggest a faith-based and spiritual approach helped interviewees feel grounded, calm, resilient, and present in difficult environments. Participants experienced a resolute identity, space for self-care, as well as access to community, belonging, and connection across national, faith, and spiritual boundaries. Results raise the importance of de-stigmatizing faith-based and spiritual coping and invite further discussion among practitioners.
\end{abstract}

"... look around for that goodness. Like that small flower or the treat someone brought you" (Aid worker, Iraq).

\section{Introduction}

Today's global humanitarian needs are higher, more complex, and more difficult to fulfil than ever before. Resources are under a lot of strain, and one major resource in the aid world are the people itself who deliver such aid: humanitarian and development aid workers who continue to 'stay and deliver' in the most difficult and dangerous circumstances (Jackson \& Zyck, 2017; OCHA - UN Office for the Coordination of Humanitarian Affairs, 2011). Living and working as an aid worker comes with many physical and psychological challenges. This paper will discuss the implications for aid workers' mental health and their potential responses to cope with

* Correspondence: ozgul.ozcan@gmail.com

Clinical Psychology, School of Health in Social Science, University of Edinburgh, Teviot Place, Edinburgh EH8 9AG, UK psychological difficulties. It will present two of the major challenges being a reluctance to acknowledge mental health issues and more so a reluctance to acknowledge diverse approaches to mental well-being in the aid world. This research will outline and discuss (a) the pervading reality of mental health challenges in the aid world and (b) a hesitance vis-à-vis faith and spiritual coping as a valid coping mechanism, demonstrating a lack of a holistic approach to aid workers' well-being. This is even more pertinent as this coping mechanism is widespread among staff and populations in the countries where much of the aid work is delivered (Cardozo et al. 2013; Pew Research Centre 2015). The paper aims to demystify faith-based and spiritual coping, demonstrate its mechanisms and argue for such coping not to go unnoticed or under-utilized when discussing mental well-being needs of aid workers and holistic responses. Outcomes of this research call to remove stigma regarding expression of emotion, needs, and mental health issues as well as stigma regarding faith-based and spiritual coping.

\section{Springer Open}

(- The Author(s). 2021 Open Access This article is licensed under a Creative Commons Attribution 4.0 International License, which permits use, sharing, adaptation, distribution and reproduction in any medium or format, as long as you give appropriate credit to the original author(s) and the source, provide a link to the Creative Commons licence, and indicate if changes were made. The images or other third party material in this article are included in the article's Creative Commons licence, unless indicated otherwise in a credit line to the material. If material is not included in the article's Creative Commons licence and your intended use is not permitted by statutory regulation or exceeds the permitted use, you will need to obtain permission directly from the copyright holder. To view a copy of this licence, visit http://creativecommons.org/licenses/by/4.0/. 


\section{Danger and stressors for aid workers}

Aid workers by nature of their work in unsafe and threatening environments are regularly exposed to situations that may have a negative and long-lasting impact on their psychological well-being (Bryant 2006; Mao et al. 2018; Musa and Hamid 2008). Practitioners publish statistics that exemplify the physical dangers: in 2016, nearly 290 aid workers were injured or killed in nearly 160 security incidents reported globally, and in 2017, this number rose to over 310 aid worker victims, including kidnappings, across 22 countries (Humanitarian Outcomes 2017, 2018). Aid workers face higher death rates than military personnel in peacekeeping operations (Stoddard et al. 2009) and are increasingly seen as legitimate targets (Sheik et al. 2000). Three kinds of stressors for aid workers have been identified (Cardozo and Salama 2002): traumatic, chronic, and organizational. Traumatic stressors include experiencing or witnessing first-hand situations that are life-threatening, direct attacks on one's own person (physical or sexual assault, rape) or on offices, accommodation, restaurants, or the incessant threat thereof; bombings, the use of improvised explosive devices, and war in the immediate vicinity, as well as indirect exposure by, for example, encountering mass graves or witnessing people die of malnutrition (Eriksson et al. 2015), and listening to the traumatic experiences of colleagues or of people in need (Connorton et al. 2011). Chronic stressors include hardship living or environmental factors, such as lack of privacy, movement, or medical care. Organizational stressors include dysfunctional management and team issues, such as constant staff turnover, an overwhelming workload, unpredictable contracts, unclear terms of reference, or under-resourcing (Antares Foundation 2012; Connorton et al. 2011). A longitudinal study shows that a typical international humanitarian aid worker experiences at least one to two traumatic events during a single field deployment (Antares Foundation 2012). Cross-sectional studies across Guatemala, Jordan, Sri Lanka, and Uganda of nearly 1200 national staff reveal that national staff, often survivors of war or disaster themselves, may suffer from additional stressors compared with international staff (Ager et al. 2012; Cardozo et al. 2013; Eriksson et al. 2013b; Putman et al. 2009).

\section{'Occupational risks'-implications for mental health}

These concrete 'occupational risks' and stressors suggest that aid workers' mental health, too, may be threatened. Various studies showed a greater prevalence of affective disorders, post-traumatic stress symptoms and disorder among aid workers than among the general population in the US or western Europe (Cardozo et al. 2005; Connorton et al. 2011; Eriksson et al. 2013a). Similarly, a Global Well-Being Survey conducted in 2015 across 11
United Nations entities worldwide showed that about half of the surveyed 17,000 staff members, aid workers, and others had mental health symptoms requiring follow-up and higher levels of depression, anxiety, or post-traumatic stress (UNS - United Nations System, Chief Executive Board for Coordination, High-Level Committee on Management 2018). A longitudinal study covering 154 staff from 17 nongovernmental organizations (Cardozo et al. 2012) demonstrated that occurrence of anxiety, depression, and psychological distress were higher after field deployment than before. Prevalence of increased depression, psychological distress, and lower life satisfaction persisted when measured 6 months after deployment, signifying longer-term impact. A phenomenological study (McCormack and Joseph 2013) of the experiences of two humanitarian aid workers post-mission emphasized the "long-term psychological distress including shame, moral doubt, betrayal and narcissistic coping" (p.147).

\section{Do aid organizations talk about mental health?}

Aid worker anecdotes and blogs note the prevailing 'cowboy' culture (Edwards 2017) which requires aid workers to overcome direct or secondary trauma "as if nothing happened" Ten years ago I was sent to DR Congo as an aid worker without security training 2017, p.4). Alternatively, the industry's culture may deem aid workers unfit for the job (Young 2015). Scientific studies, too, highlight the "macho' culture of denial" of the psychological impact of aid work (Barron 1999; Ehrenreich and Elliot 2004, p.55). There is no evidence that aid workers receive regular, special training for secondary trauma-defined as the "natural consequential behaviours and emotions ... resulting from knowing about a traumatizing event ... and the stress resulting from helping or wanting to help a traumatized or suffering person" (Figley 1995, p.7)-despite high exposure, reported by over 60 and $80 \%$ of aid staff in Uganda and Sri Lanka, respectively (Ager et al. 2012; Cardozo et al. 2013). Pre-mission trainings usually do not include psychological first aid despite availability of training manuals (World Health Organization 2011) or the recommendation to seek psychological support before, during, and after deployment (Connorton et al. 2011; Cardozo et al. 2012). Although mental health issues are a regular occurrence and a 'normal' reaction to abnormal situations people face (Bjerneld et al. 2004), less than half of the 376 national aid workers in Uganda across 21 humanitarian aid agencies reported the existence of psychological support systems in their organizations (Ager et al. 2012). However, recent developments look promising: agencies place increased emphasis on, and enhance access to, mental health services (Antares Foundation 2012; Cardozo et al. 2005; Eriksson et al. 
2009; Eriksson et al. 2013a; UNS - United Nations System, Chief Executive Board for Coordination, HighLevel Committee on Management 2018; WeltonMitchell 2013). This is in line with agencies' 'duty of care' principles that aim to attenuate predictable risks, particularly in high-risk environments that may place staff in harm's way (Creta 2018). Practically, these principles are not only expressed in the provision of armoured vehicles and bullet-proof vests but also policies on occupational safety and health. The well-established origins of the concept stem from a UN General Assembly Resolution calling to ensure fullest measures of protection for UN agents (UNGA - United Nations General Assembly 1948). While not every agency offers a psychosocial support policy or direct and immediate access to a counsellor due to resource, logistic, or security restrictions, practitioners concede that while caring for people in need, it is crucial to care for their own staff, too (IASC - Inter-Agency Standing Committee 2007).

\section{Moderating factors and coping}

Exposure to aid work risks and psychological distress can be moderated by support systems, positive attitudes towards seeking help, or other coping mechanisms to protect psychological well-being (Connorton et al. 2011). One such mechanism is religious coping which is defined as "the use of religious beliefs or behaviours to facilitate problem-solving to prevent or alleviate the negative emotional consequences of stressful life circumstances" (Koenig et al. 1998, p. 513).

For the purpose of this research, religious coping shall include aspects of faith and spirituality which are understood as a sense of meaning, purpose, and hope (Peres et al. 2007) related to a connection with God or gods, nature, or a life force. Faith-based and spiritual coping among aid workers has not been extensively researched despite the altruistic nature of aid work: in line with faith-based principles of service and altruism, 96\% of 214 aid workers across 19 Nongovernmental Organizations indicated prior to their deployment to be motivated to "contribute to a better world and help those less fortunate" (Eriksson et al. 2013a, p.45). Faith and spirituality remain important across cultures, particularly in many countries where international and national aid workers operate (Pew Research Centre 2015). Despite this awareness, there is a risk that faith and spirituality are viewed unfavourably. As an example, the head of the ethics office of a major humanitarian organization claimed spiritual aspects remain explicitly excluded in day-to-day office life (personal communication, 6 March 2018).

Research into the use of faith-based or spiritual practice has yielded mixed results. Some studies do not show correlations between a faith-based or spiritual practice and better mental health outcomes (Connor et al. 2003; Ellison et al. 2014; Fitchett et al. 1999; Kirkpatrick et al. 1999; Pargament et al. 2001). However, there is a growing body of evidence that establishes the benefits of a faith-based or spiritual practice on mental and physical well-being (Koenig 2001; Moreira-Almeida et al. 2014; Seybold and Hill 2001). For example, research has found positive correlations between mental health, cognitive capacities, and physical health with the frequency of prayer (Maltby et al. 1999) and attendance of religious services, giving the comfort of a social support group (Dein et al. 2012; Ellison and Fan 2008; Ellison 1998; Hackney and Sanders 2003; Koenig et al. 1999). Hourani et al. (2012), analysing data collected from 24,000 randomly selected active US military personnel, demonstrated that high spirituality had a significant protective effect for depression symptoms.

In addition, aid workers self-report the use of faithbased and spiritual practices as a coping mechanism. In a study of Sri Lankan national aid workers, over 55\% of 398 workers surveyed on factors affecting mental health highlighted religion as an important coping mechanism for stress (Cardozo et al. 2013). This is in line with research as whole; a meta-analysis of 49 relevant studies on religious coping and psychological adjustment to stress, including several studies with longitudinal design, such as Pargament et al. (1994) or Tix and Frazier (1998), shows that religious coping methods are reliably correlated with better psychological outcomes, hope, stress-related growth, less depression, anxiety and distress, etc. (Ano and Vasconcelles 2005). A systematic review of four qualitative and seven quantitative studies (Shaw et al. 2005) noted that religion and spirituality were usually beneficial to people dealing with the aftermath of trauma. Trauma and recovery studies recommended research to "include a focus on spiritual issues and spiritual well-being" (Park 2017, p.305). Mental health practitioners are encouraged to introduce spiritual and religious practices in psychological interventions for coping with trauma, e.g. among refugee women (Smigelsky et al. 2017). Empirical research showed such practices reduced burnout in clergy (Eriksson et al. 2009). Psychologists reported that spiritual and religious issues were relevant in their practice $83 \%$ of the time, with the majority recognizing the beneficial aspects of religiosity and spirituality for individuals (Delaney et al. 2007).

However, the intersection between potentially traumatic events, living and working conditions of aid workers, and their faith and spirituality remains very specific and empirically and qualitatively underresearched (Currier and Eriksson 2017). This study qualitatively examines the interplay of these aspects among female aid workers. The outcomes provide employers, therapeutic practitioners, and other aid workers 
with insights into how aid workers with a faith-based and spiritual practice cope in stressful living and working environments in conflict or disaster-affected areas. It reveals how aid workers experience the challenges of their context and how their practice contributes to their well-being and the specific mechanisms thereof. Speaking about faith and spirituality may be very intimate and not self-evident to generalize and quantify (King and Crowther 2004; Wartenweiler and Eiroa-Orosa 2016); therefore, qualitative research was selected as the most appropriate design to give voice to aid workers' experiences. This qualitative research moves beyond the realm of anecdotes and provides insights into the depth of the lives of aid workers. Through inductive thematic analysis of semi-structured interviews, this paper allows an exploration of the experiences of these female aid workers without reducing collected data to numbers (Pyett 2003; Silverman 2000). Acknowledging the importance of context in which aid work, faith, and spirituality are experienced, this design is adequate to study personal, potentially traumatizing experiences and pursue vulnerable discussions about faith, spirituality, God/gods, prayer, community, etc. with the "desire to know people's own perspectives and meanings" (Braun and Clarke 2013, p.21).

\section{Method}

\section{Participants}

Participants were recruited through personal networks and an aid worker social media forum with 19,000 members. Purposive sampling narrowly followed the inclusion criteria of being female aid workers, regardless of nationality, duty station country, or type of contract, having worked in a conflict or disaster-affected area within the last 5 years and following a faith-based or spiritual practice or life approach. The latter criterion was held deliberately wide due to the intimate, individual nature of these concepts. Faith and spirituality were defined as a sense of meaning and purpose, hope, and faith which could be an explicit belief in God, feeling connected with nature or the force of life, or a collection of clear values, transcending the self (Drescher 2006; McKay 2010). All participants with a self-reported practice or life approach were interviewed. Inclusion in this study was deliberately limited to female aid workers with the aim to support homogeneity in the data. While some research highlighted how different genders experience challenges in aid work differently (Armagan et al. 2006; Holtz et al. 2002), this was not a factor in focusing on women. Longitudinal studies (e.g. by Cardozo et al. 2012) on psychological distress, depression, anxiety, and burnout among international humanitarian aid workers, involving 59\% women, did not find gender differences. Purvanova and Muros' meta-analysis on burnout (2010) covering 183 studies reveals that both genders suffer burnout, with women being slightly more emotionally exhausted and men slightly more withdrawn or cynical. However, the deliberate choice to limit this study to women in line with principles of homogeneity aimed to give a detailed insight into the specific phenomenon of religious coping. A focus on women enabled a detailed investigation of processes relating to the research question on religious coping (Ritchie et al. 2003); Chan and Rhodes' (2013) analysis of multiple studies summarized that religious coping is more common among women. Other, qualitative studies show the importance of spirituality in women for overcoming trauma, e.g. childhood abuse (Shaw et al. 2005). This study wanted to take advantage of outcomes of such prior research to achieve clear results that were not potentially modified by a gender factor. A total of 14 participants from seven countries and six faith and spiritual backgrounds were interviewed and fulfilled all criteria. The sample size is adequate and in line with criteria for qualitative research (Vasileiou et al. 2018). Participants included three women acquainted with the researchers prior to the study which required managing a dual relationship. This meant interviewers carefully balanced relationships with interviewees as colleagues/acquaintances and as independent researchers during and after interviews (Garton and Copland 2010). One participant each originated from Australia, India, Philippines, Syria, and an undisclosed Asian country; three were from the UK, and six were from the USA with varying ethnic backgrounds. Nine participants identified as Christian, and five participants identified as Christian-Buddhist, Hindu, Muslim, Muslim-Buddhist, Yogini, and Meditator, respectively. Their practices varied from daily or occasional prayer, Scripture studies to nature contemplations, yoga, and insight meditation. They ranged in age from 29 to 48 years $(M=37)$. Eleven participants have worked as international aid workers (i.e. in countries other than their own), two participants have worked as national aid workers, and one participant has worked nationally and internationally. The field duty stations the aid workers have worked in and mentioned during the interviews span across the globe: Afghanistan, Armenia, Bangladesh, Bolivia, China, Democratic Republic of the Congo, Djibouti, Egypt, Ethiopia, Haiti, India, Iraq, Jordan, Kenya, Lebanon, Libya, Myanmar, Nepal, Pakistan, Palestine, Philippines, South Sudan, Sri Lanka, Syria, Tunisia, and Uganda.

\section{Procedures}

In line with ethical standards (British Psychological Society 2018), researchers provided information about the project, obtained participants' consent, and offered the option to ask questions, raise complaints, and withdraw at any point. Additional resources for mental health and 
psychological support specific to aid workers were shared after the interviews.

\section{Data collection}

Data were collected in semi-structured, confidential, one-to-one interviews respecting the personal nature and sensitivity of the topic and allowing for an open and flexible discussion. The interview guide covered aspects of aid and spirituality and was discussed with a mental health counsellor of a major international humanitarian organization for reality cross-checking before application (Smith 1995). The conception of open-ended questions avoided any predetermined themes (Terry et al. 2017). The interviews were audio-recorded, transcribed verbatim, anonymized, and approached with thematic qualitative analysis for prevalent and repeating themes (Braun and Clarke 2006).

\section{Reflexivity}

The research team have all had experience in aid work in both sectarian and non-sectarian settings. In an attempt to facilitate discussion, the primary researchers did disclose previous aid work experience. In addition, the data collection was completed by women researchers with the hope this would alleviate any issues around gender. Despite the research team's personal and spiritual background, specifics were not divulged during the research process to avoid the perception that only positive outcomes regarding spiritual coping were sought. This research team acknowledged that individual experiences were part of a broader social and cultural context that have shaped and validated this research interest (Lazard and McAvoy 2017). Coming from both aid work and faith-based experiences allowed for a familiarity and connection with participants. However, previous sectarian and non-sectarian experiences of the research team or experiences of spirituality as protective mechanism may not reflect the participants' experiences. Consequently, the researchers acknowledged the potential of negative effects of a faith-based and spiritual practice. This was managed by paying attention to explicit and implicit bias to encourage as much neutrality as possible.

\section{Analysis approach}

Using thematic analysis as a very flexible yet systematic approach to qualitative research allowed for identification, analysis and reporting of codes and themes within the data, independent from theory or epistemology (Braun and Clarke 2006). While the ramifications of working in aid and the model of spiritual coping are acknowledged and part of the research questions, the analysis of the participants' experience was inductive and data-driven. As per the contextualised method, this analysis made space for the reality of the participants and their meaning-making while acknowledging the wider social and political context of aid work that may influence their experience and interpretation. The digital theme map demonstrates the grouping and relationship of three themes (see Fig. 1).

\section{Results}

Three themes were identified in response to the research question how a self-reported degree of faith or spirituality may contribute to better coping in the face of stressful living and working environments in conflict or disaster-affected areas. To understand the phenomenon of faith-based and spiritual coping in aid work, the first theme outlines the overall context of working in the aid world: a demanding environment that requires non-stop full capacity of its workers (The context: The aid 'world'). The second theme outlines the primary outcome, benefits and gains, of faith-based and spiritual practices, and the underlying supportive processes reflected in respecting one's values and needs ('Filling one's own cup'). The third theme outlines secondary, negative implications of such practices that might threaten one's balance (When the cup has a crack).

\section{Theme-The context: the aid 'world'}

This theme provides a frame of reference for the experience of participants. It highlights in three subthemes their faith-based or spiritual motivations to enter the profession, its demands, dangers, and psychological impact, as well as the culture of aid work.

\section{Subtheme: motivation and expectations}

For many participants from different faiths, a main motivation lay in the desire to reach "those who are underserved.... I would say yes, my faith plays a big part in that" (participant 14). Participant 12 saw aid workers motivated "by something bigger than themselves". Participants wanted to "serve humanity" (participant 11) and "be a part of a solution" (participant 7) presented by aid work.

"You have to do right and you have to protect people from being harmed .... when I stand (before) God... I will not be asked: 'You had the chance ... to help somebody in this situation, why didn't you do it?"' (participant 9)

Some participants experienced a parallel between faith and the fight against injustice and poverty with " $a$ realisation that goes along with faith: ... before my life is over I really need to try and reduce that extreme poverty" (participant 5). Many participants spoke of the love they felt for and from God or a Higher Power, of being an 


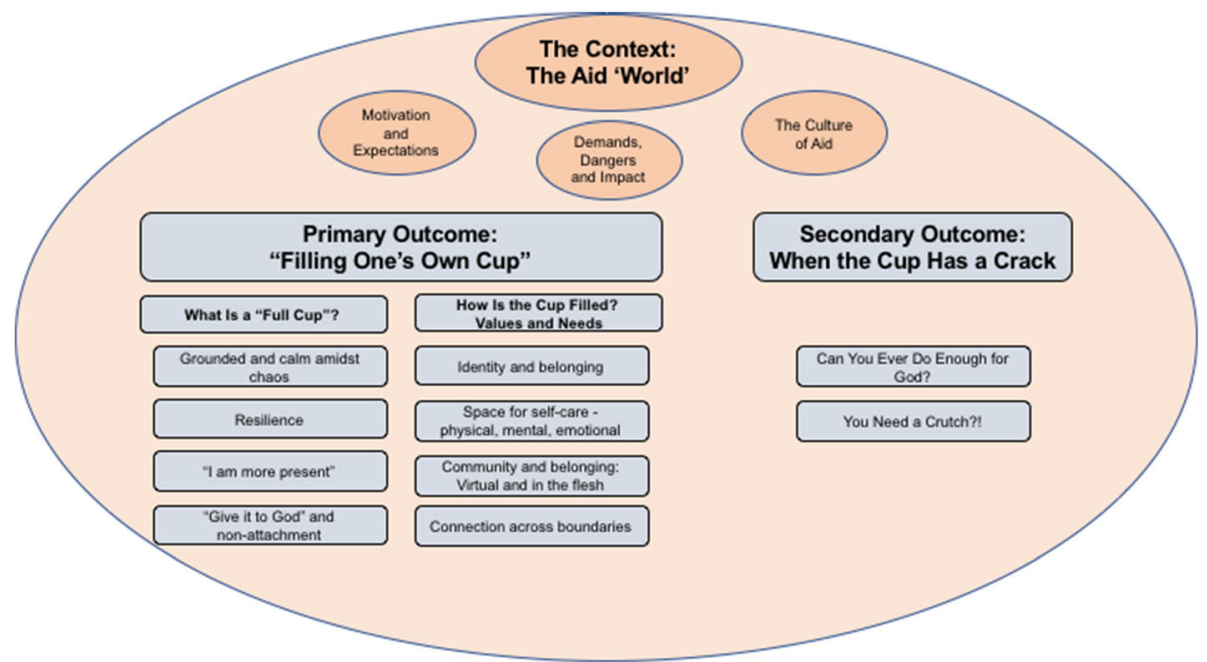

Fig. 1 Theme map

"instrument" thereof through their work (participant 2) and of "extending love from that" (participant 4). They acknowledged that they "have a responsibility to act lovingly" and did so empathically (participant 12) in the context of their aid work.

\section{Subtheme: demands, dangers, and impact}

Working in aid, particularly in humanitarian aid, participant 4 noted that "the expectations are so high... everything is an emergency...there is no such thing as personal time", and subsequently, there was not much time for reflection. Statements about "crazy hours ... crazy living conditions, ...crazy risk disaster environment" (participant 5) summarized the demands. Aid workers were expected to react with flexibility, versatility, and inventiveness in all situations: An immediate travel request for an emergency response operation was answered with ' $n o$ problem' and I basically packed my bag. The next morning, I was on a plane" (participant 11). "There were no security plans for things like ... if we were attacked, so all of us ... were constantly trying to come up with our own plans" (participant 6). While being faced with a "pile of dead bodies" (participant 5), refugees and internally displaced persons' dire living conditions (participant 1), suicide attacks on project sites and accommodation (participants 6 and 12), threats of kidnapping and sexual assaults (several participants), aid workers were exposed to both direct and secondary trauma. Participant 7 noted after a traffic accident "mobs will just hack you, and we saw a number of people killed that way". Under such conditions, aid workers were left "burnt out" (participant 3), drained of "not only physical energy but emotional and spiritual" (participant 14) and subject to "anxiety" (several participants), unprocessed grief and trauma, and the isolation of having to "manage it alone" (participant 2). After many humanitarian emergency missions without the space to reflect and release emotions or recharge spiritually (participant 14), participant 5 claimed "there's a bit of me that's dead", one potential response to secondary trauma.

\section{Subtheme: the culture of aid}

Aid workers had a reputation of being courageous and efficient, "they go in, they stitch people up, they deal with any ...emergency" (participant 11). They were known to successfully accomplish their "fast-paced work where decisions need to be made very fast" (participant 2). Part of the culture also was the never-ending nature of work and how "people become workaholics because you have to give your life to it, almost" (participant 4). Several aid workers spoke of the 'cowboy' or 'cowgirl' image of aid workers who were

"not afraid of going...into the warzone... we're tough... Everyone was burnt out and everyone had secondary trauma and yet no one would admit it... we just had no option... there was ...no way to talk about it in our office, for we were just ... berated for being weak ... and that we just needed to get the job done" (participant 3)

Participants experienced the culture as one of bravery but also stigma where coping through potentially selfdestructive behaviours seemed more accessible than sharing psychological struggles or how they coped better thanks to their faith or spirituality (participant 4). Participant 6 and others observed potentially adverse coping mechanisms such as "alcoholism, ...drugs,...indiscriminate sex...a wild lifestyle that accompany aid work 
especially in conflict countries because that's the way that people choose to deal with their stress".

\section{Theme-The primary outcome: 'filling one's own cup'}

A crucial thread seemed to be expressed in the theme of 'filling one's own cup': "You really have to realise I need to fill myself up so I can give to others" (participant 14). Two subthemes with four components each denote (a) what a 'full cup' meant to them and (b) what mechanisms were used to fill the cup, i.e. what aspects of their faith-based or spiritual practice specifically recharged the participants.

\section{Subtheme: What is a 'full cup'?}

Participants experienced varying states and emotions when their 'cup' was filled.

Component 1: grounded and calm amidst chaos Overwhelmingly, participants with a faith-based or spiritual practice felt calm, reassured, and certain that "things ... will be ok" (participant 1), grounded versus "unrooted" (participant 4), "sheltered" (participant 10), and centred and equanimous (participant 11). Participant 1 recounted that her practice intensified while stationed in the field to achieve a sense of calm and "stability" in direct relation to the increasing chaos around her.

"Something that you do regularly adds balance to your life and as an aid worker there is not a lot of balance and there is not a lot of consistency... so ... just the daily practice of being faithful brings some order to the chaos ... (laughs) that is our lives" (participant 6)

Confronted with suddenly losing her job, one participant noted:

"When you're in the humanitarian world, if you lose your job, you lose everything, you lose your house, ... health insurance, ... income, you lose your country because you're in that country for your job... you lose everything basically and... if I did not have faith, I would not be able to explain that,...but instead I had a really positive attitude" (participant 4)

Component 2: resilience Participants' practices fed their resilience and ability to withstand (e.g. secondary trauma) (participants 11 and 14) or "bounce back" (participants 6). Faith "forces you to look around for that goodness... When I was in a place where we saw so much darkness I really felt a lot of light" (participant 14). After "spending some time with God", participant 2 remained persistent and refused "giving up", while participants 3 and 7 noted that their "connection to God" kept them going and continue in aid work. It "made me stronger and more able to deal with the refugee stories that we'd hear every day" (participant 7).

Component 3: "I am more present" The practice across different faith traditions, while acknowledging the temporary nature of this world, also enhanced the ability to deal with death, grief, and stories of violence and sexual assaults (participants 8, 9, 10, and 11). Recounting the strength of raped Congolese survivors, participant 7 remained hopeful despite such hardship: "God is still with us, and listening and answering... That presence is the promise". Participants felt that their practices enabled them to listen better and be "more present with the people I was interviewing in the camps" (participant 11), to be a "balm to the wound" (participant 7) and be able to "walk with people as they were suffering" (participant 3). Without her spiritual practice, participant 1 notes "I wouldn't have found my job as fulfilling. I wouldn't have been as good with refugees... and able to give them the time that they needed".

Component 4: "Give it to God" and non-attachment Participants felt their balance was restored when they practiced in moments when they did not have control over their environment (participant 1). They conceded that "God is in control" (participant 7), and they are "powerless in the scheme of the Universe and ... release it to a Higher Power" (participant 13). Participant 11 experienced rest in a place of "complete acceptance whether it is joy or suffering". Knowing that they were not in charge of events that were beyond any human control provided a certain relief.

"Knowing my limitations ... was like a moment of humility ... because ... often we want to fix it, ...especially as aid workers, ... seeing all the suffering, ... I just have to be able to say I can't do anything more ... In those moments, I have to trust God" (participant 3)

Participant 10 and others noted: "I could die anywhere when my time's up", and therefore felt non-attached and safe, including in challenging security contexts.

\section{Subtheme: How is the cup filled? Values and needs}

This subtheme expressed the particular mechanisms which are specific to participants' faith-based and spiritual approach and which caused the 'refill' to enable them to better cope. 
Component 1: identity and belonging Many participants' identity was strengthened by their faith and their spiritual practices-they were able to rely on a sense of self beyond their identity as aid worker or colleague, so that when they felt isolated, overwhelmed or ineffective as aid workers, their psychological balance was less affected. Participants felt strongly about this sense of self which carried them beyond the destruction and temporary nature of the aid context. They had their own "sense of person in the midst of this chaos" (participant 5). Participant 6 noted that if she did not know her "place in the world, I... am quite sure that I would still be in a very difficult recovery time even... now, nearly two years after I left that situation". Participant 3 felt that her resilience would be stronger if she were truer to her faithbased identity and if she were "actually 'being out' with my spirituality". While their practices gave participants a stronger sense of identity, it also gave a sense of "positive energy, you connect with that, ...that is much bigger than who you are, that ...defines you as a person" (participant 8 ) and thus also helped them feel a sense of belonging to something bigger.

Component 2: space for self-care-physical, mental, emotional In their work context, space was not always available, be it physical space, such as living quarters and choice of housemates (participants 12 and 14), or space to process the demands, dangers and impact and to acknowledge the related emotions:

"I can deal with humanitarian response stuff but I can't deal with having feelings and emotions at the same time. You have to sort of... shut down... You have to shut that bit down really, to be able to deal with it" (participant 5).

A faith-based or spiritual practice supported and facilitated the creation of metaphorical space for self-care on the physical, mental, and emotional levels. Participant 11 experienced her meditation practice as a life-guard for her physical health as it "prevented further damage that may never have been able to be repaired", and participant 1 "would have continued to engage in things that were more self-destructive than helpful to me" without her yoga practice. Participant 4 admitted she "would have drank a lot more, I would have smoked a lot more" without her faith, while participant 3 felt her centering prayer practice made her "just able to ... take steps back... I'm not so in it and emotionally ... invested". Pursuing their practices was "carving out that bit of the day for me, but it's also a way of processing and acknowledging emotions" (participant 5). Her practice gave her "the freedom and the ability... to ... observe it neutrally and then, take action" (participant 13).
Component 3: community and belonging: virtual and in the flesh The experience of community, of not being alone but sharing commonalities with others, of being supported and of belonging were major needs for many aid workers. This was especially important when the usual social network of family and friends was unavailable due to the distance or 'unrelatability' of their lives or experiences, and participants could not "talk to them about my struggles in the field" (participant 4). People were seeking community, "I needed to be in mixed company, I needed to be drinking, I needed to be laughing... that's how I dealt with that situation" (participant 8). While adverse coping mechanisms such as the overconsumption of alcohol was a tool of bonding and "this big thing that we had in common" (participant 11), some participants felt excluded: "So if I didn't want to get shitfaced it was like 'oh, she's more (local)' or ..., 'she's Asian and therefore not one of us'” (participant 10).

A faith-based and spiritual practice fulfilled this need of community in other forms. First, some participants felt they had a "very personal relationship with whatever...you call...the Higher Power" (participant 8) or a "relationship with God,...being connected to God" (participant 2). In such, they were "having Someone to rely on" (participant 4). Then, participants fulfilled this need for community by joining or creating spiritual or prayer groups in their field duty stations (participants 6 and 12). An alternative to in-person community participation included virtual/distance prayer groups (participants 3 and 6) or online meditation communities: "We would practice meditation on Skype and they became my community" (participant 11) and thus participants' practices effectively helped create their own faith-based or spiritual social support systems and community.

Component 4: connection across boundaries In line with the felt sense of community was the connection across the experienced divide between nationals and internationals, staff and other, and across faith boundaries. "So you all have your own take on it and you all come from very different backgrounds ..., all of that can be hard but if you have something in common it helps bring it together" (participant 14). A faith-based or spiritual approach and identity created an environment where national and international aid workers of different spiritual practices, beliefs, languages, and cultures could connect and discuss (participant 8). This felt connection enabled a Christian international aid worker to respond to a Muslim national aid worker to "just pray and Allah will give you a dream" and to "have those conversations about faith" (participant 5).

Most participants felt being more accepted, integrated, and respected by national colleagues for having a faithbased or spiritual practice than by international 
colleagues: "They were delighted that I had a faith" (participant 5), "they saw it very highly ... because all of them ... value their faith and see it as an essential part of their life and identity and so seeing me as a Westerner who actually had faith meant a lot to them" (participant 4). Participants felt connected through their shared humanity (participants 3 and 8 ).

"Like, we're not different, we're really not. We're the same seed in different soil and we've had different inputs from our cultures... but in our experiences and things like that, there's something...in all of us humans that I wanted to understand more of, because of my faith" (participant 7)

Theme-Secondary outcome: when the cup has a crack This theme covers potentially adverse consequences of a faith-based and spiritual practice.

\section{Subtheme: Can you ever do enough for God?}

A related aspect to the subtheme of motivation which increased the burden on faithful or spiritually minded aid workers was the question if you can ever "do enough for God" (participant 5). There might also be an additional burden of "representing a good, religious person ... with a responsibility for my faith" (participant 9). Participant 3 conceded "that connection with God... drove me to ... probably push myself when I needed to maybe step back and take some time ... to work out whatever I was feeling". This aspect demonstrated that some parts of a faith-based or spiritual approach might increase the chance of burnout, rather than relieving it and 'filling your cup'. In line with their motivation and the culture of aid, "often ...we expend ourselves" (participant 3) and "often ...we do get burnt out...we start thinking things are not going to work without us" (participant 12).

\section{Subtheme: You need a crutch?!}

Many participants noted that the international aid environment was less welcoming to expressions of faithbased or spiritual practices (participant 4). Participant 1 experienced lack of acknowledgment of the value and benefits of a spiritual practice: "It's kind of like 'Science vs. Spirituality" and participant 13 experienced attitudes in the West as "sneery about the positive ...effects". Participant 7 noticed a "general sense of ambivalence or apathy towards" her faith and some even felt ridiculed:

"none of my colleagues were faith-based people... or had any faith, ... and so... it was something like, 'oh, did you not study in school that there is no God?', ... basically saying that even though ... I have the same credentials as them, I have my Master's degree, I'm educated and ... there is no difference in terms of that ... but they just saw it (as) kind of dumb ... or childish or immature or ... I have to rely on a 'crutch' ... for dealing with things" (participant 4)

Regarding not engaging in adverse common coping mechanisms to "let off steam" (participant 6), some also feared judgment and felt that they did not "want to be judged for my faith, saying ... I don't want to do this for this and this reason, so that's a challenge" (participant 4).

\section{Discussion}

\section{Summary and synthesis}

The study expected to find how a self-reported degree of faith or spirituality may contribute to better psychological coping in the face of stressful living and working environments in conflict or disaster-affected areas. Inductive thematic analysis of 14 semi-structured interviews revealed three related themes, "The context: The aid 'world", the "Primary outcome: 'Filling one's own cup", and the "Secondary outcome: When the cup has a crack". The findings reflect previous quantitative research with large and varied samples on religious coping and its multidimensional character (Pargament et al. 1998): Findings suggested that a faith-based and spiritual approach provided participant aid workers with a groundedness and calm amidst an environment of chaos and direct and secondary trauma. Participants gained a sense of enhanced resilience and ability to be present for their personal needs, work demands, and the needs of people they served. A faith-based and spiritual approach allowed participants to let go of the impulse to try and control every situation that arose in the aid context but other times also challenged them to push themselves beyond their capacities. To some degree, participants experienced ostracism due to their faith and spirituality. The identified supportive mechanisms were represented by the participants' strong identity characterized by their faith-based or spiritual beliefs, the availability of community support, and the connection experienced across cultural, national or faith-based and spiritual boundaries. An important mechanism was revealed by the creation of emotional processing space following exposure to stressors and direct and secondary trauma.

\section{Outcomes reflected in psychological theory}

Some of the supportive mechanisms and related outcomes revealed in this research are reflected in certain psychological theories, e.g., in the framework of the mindfulness-based Acceptance and Commitment Therapy (ACT) (Hayes 2004; Hayes et al. 2001; Hayes et al. 1999). Participants viewed themselves as self-as-context through a solid understanding of their identity, a 'continuous sense of self' (McLean and Follette 2016, p.145). 
This means their sense of self was not determined by the limiting context they lived or worked in. Rather, their sense of self determined how they viewed their context. Their aid experiences did not restrict participants' sense of personhood. Rather, their identity as faith-based or spiritual persons, in instances, supported them to continue their work in the aid world while being in line with their own values (Hayes et al. 2006).

Escaping and avoiding emotions, thoughts, and memories is "one of the most pathological processes known (as)...experiential avoidance...even when the attempt to do so causes psychological harm" (Hayes 2004, pp.649650; Hayes et al. 1996). Accordingly, by practicing their faith and spirituality, participants gained the chance to accept and process these emotions, thoughts, and memories by taking space for self-care, instead of engaging in experiential avoidance. This could decrease the occurrence of psychological harm (Hayes et al. 2006). The more control someone has over their work, the lower their stress levels (Bond and Bunce 2003). In the aid context, participants outlined that such control was not always available, given war and conflict situations, direct or secondary traumatic events. However, they felt a groundedness and greater ability to be present for themselves and for others by accepting certain circumstances as beyond their control. They acknowledged their lack of control which, indeed, may protect from burnout (Johnson 2001; Maslach and Jackson 1981) and psychologically accepted related emotions (Bond and Hayes 2002).

\section{Social support in community and connection}

In line with social psychology research, participants' experiences reflected the need to belong (Baumeister 2012): Their practice enabled them to be part of and to create communities, both in-country and virtually, as well as building connections to the people in the countries where they worked. Participants' feelings of being 'sheltered' and supported as part of prayer or meditation communities is in line with previous research on the impact of religious communities (e.g. Nicholson et al. 2009). Social support sustains mental health through e.g. a regular joint spiritual practice (Hill and Pargament 2003), which, over time, can enhance resilience (Comoretto et al. 2015). While religiousness and social support do not necessarily correlate positively with each other in secular contexts (Kvande et al. 2015), the latter is not the contextual reality of the majority of the world population-about $90 \%$ actively pursue some form of religious or spiritual custom (Schafer 2010; Pew Research Centre 2015). This indicates that such practices may be important and beneficial to social support in most global contexts, for example for national aid workers. Feeling connected across cultural and religious boundaries was not ubiquitous but sufficiently important and rewarding for participants' well-being. The connections, thanks to their beliefs and practices, across what some of them perceived as a separation between national and international staff were particularly meaningful in the context of aid challenges and culture.

\section{Implications for policy and practice}

Aid organizations have power in removing stigma around mental health difficulties and in challenging such stigmatization which was regarded part of aid culture (McCall and Salama 1999).

\section{Removal of stigma regarding expression of emotions, needs, and mental health}

The demands in the aid world require aid workers to successfully deliver projects to save lives. The endeavour to fulfil high expectations while neglecting personal needs without adequate physical, psychological, or social organizational resources may lead to higher levels of burnout (Bakker and Costa 2014). The head of the ethics office of a major humanitarian organization noted "a gap between what some people believe and do in their personal life - mindfulness, faith-based and therapeutic interventions - versus what they bring in to their professional lives: There is no holistic approach that would include our emotions, body sensations, etc. There is an alarming 'illiteracy' in dealing with emotions and in reading one's own emotions and those of colleagues, in the work place" (personal communication, 6 March 2018). Such observations demonstrate the responsibility of aid organizations for the psychological welfare of their employees (Comoretto et al. 2015): The organizational culture is a major factor in this. Connorton et al. (2011, p.147) claim "there is no evidence base regarding how to prepare relief workers for occupational trauma and stress". Admittedly, humanitarian agencies' guidelines on mental health and psychosocial support with focus on beneficiaries do suggest some actions and resources on how to "prevent and manage problems in mental health and psychosocial wellbeing among staff and volunteers" (IASC - Inter-Agency Standing Committee 2007, p.87). Some organizations have demonstrated key initiative to look into staff needs (Welton-Mitchell 2013). Agencies offer access to staff counsellors at Headquarters and field duty stations, availability of internal training materials on stress management and mental health, or organizational access to commercial mindfulness training apps (personal communication with staff counsellor of major humanitarian organization, 28 March 2018). However, more is required to institute cultural change and satisfy the psychological needs of aid workers and thus enable them to better fulfil the high work demands and achieve organizational goals. 
The potential impact of the aid work context on mental health requires more conversations, training, preventive interventions, continuous support, and debriefings. To illustrate, psychological therapists are exposed to secondary trauma through the recounts of their patients. The related recommendations for this occupational group are to engage in peer discussions and to obtain additional training on prevention and impact (Trippany et al. 2004). Aid workers, similarly exposed to secondary trauma, require e.g. "peer support networks ... during or after deployment" (Cardozo et al. 2012, p. 11) and additional psychological training on self-care. It remains important to continue working towards de-stigmatization of mental health difficulties. Organizations could support their staff through structured exercises to build community and enable environments where 'weakness' is redefined and having a 'crutch' is deemed helpful and essential.

\section{Removal of stigma regarding faith-based and spiritual coping}

Participants shared how difficult it is to discuss their faith-based and spiritual coping mechanisms with colleagues, indicating the lack of an inclusive approach. While organizations as the Headington Institute offer documentation and training on spirituality and humanitarian work (McKay 2010), it is difficult to advertise such a mechanism within aid agencies: Agencies' codes of conduct prohibit the promotion of a particular religious standpoint (Schafer 2010). However, it is important to differentiate between organizational programme delivery and personal welfare aspects. While respecting codes of conduct, agencies may address all available coping mechanisms, including faith-based and spiritual, in agency-internal stress-management trainings. For example, agencies could facilitate "time for the exercise of spiritual practices as part of recreational life and wellbeing for staff" (Eriksson et al. 2015, p.21). Psychological therapists and staff counsellors could be further sensitized on faith-based and spiritual coping, integrating it into the treatment and healing process of staff (Pargament 2012; Smith 2004). Client-driven discussions on multiple coping mechanisms should be incorporated. Agency staff counsellor teams could include interfaith chaplains to address faith-based and spiritual coping and integrate both psychological and spiritual needs of multi-cultural staff teams. As such, aid agencies would follow the examples of hospitals, mental health institutions, law enforcement agencies, and universities which offer the services of chaplains. Such steps would be particularly helpful to address the needs of national staff considering that the vast majority of aid staff are national, e.g. 95\% of International Nongovernmental Organizations' staff (ALNAP 2010), and faith is an important factor for them (McCall and Salama 1999). Opening up mental health support with spiritual emphasis for aid workers would also reflect current considerations of a faith-sensitive approach among aid organizations regarding mental health and psychosocial programming in humanitarian aid IASC - Inter-Agency Standing Committee Reference Group Mental Health and Psychosocial Support in Emergency Settings 2018). With increased attention on resilience-building among aid workers and the existence of spiritual constructs in resilience, faith, and spirituality as coping mechanisms must be recognized as important factors for aid workers' well-being and thus productivity (Peres et al. 2007; Selby et al. 2009; Wartenweiler and Eiroa-Orosa 2016).

Both "social support and organizational support each remained significantly related to less" burnout (Eriksson et al. 2009, p.682) and practitioners acknowledge that staff "who feel ...psychologically secure are more likely to be productive and engaged" (Konterra Group 2017, p.2). This indicates the importance of supportive relationships, policies, and procedures at the organizational level. Such networks are important even after aid workers' deployments end, potentially supporting faster staff recovery (Cardozo et al. 2012).

\section{Limitations}

This research outlines self-selected participants' experiences and a larger, quantitative sample would be required to enable generalization. The strength of the chosen method however is the chance to glimpse into the reality of people's lives as aid workers with a faithbased or spiritual practice, their difficulties, hopes, and strengths beyond mere anecdotes. While many different faiths and expressions of spirituality were represented, most respondents were from industrialised and Christian-majority countries. However, the recruitment through social media beyond personal networks and avoiding official organizational channels allowed a neutral and independent approach to participants and thus the data.

\section{Recommendations for future research}

This research focussed on women to obtain largely homogenous data and follow up on available research about women and religious coping. Further research could hone in on participants' specific experience as women in aid. Future similar research could target male aid workers and the potential stigma around mental health issues men may face, and their access to faith and spirituality for coping. An important aspect would be the role that faith plays among national staff and how it can be integrated in mental health-related and stress management trainings targeting national aid workers. 
Future research should target follow-up on implementation of recommendations to test their effectiveness.

\section{Conclusion}

A faith-based and spiritual practice can be an effective coping mechanism through processes that are linked to humanity's primary needs of identity, space for self-care, community, belonging, and connection. The participant aid workers' experiences revealed the potential ongoing presence of stigma around mental health challenges and this coping mechanism. An organizational and social culture change is required to acknowledge the need for and utility of this psychological mechanism. While participants here have experienced challenges in their aid work contexts despite their faith-based and spiritual practices, they also reported that they have struggled less and coped better because of their practices which were integral to their coping. Opening up the discussion and allowing space for faith and spirituality might help reveal and remove stigma and improve aid workers' well-being and thus productivity in the field.

\section{Acknowledgments}

The researcher wishes to express gratitude to each of the female aid workers who shared their stories with generosity and trust for their continuous courage and work in the field.

\section{Authors' contributions}

The corresponding author is the principal author. The co-authors have been involved in editing and advice, and data collection, respectively. The authors read and approved the final manuscript.

\section{Funding}

No outside funding was used to support this work.

\section{Availability of data and materials}

The dataset that supports the findings of this study is available on request from the corresponding author. The dataset is not publicly available due to privacy and ethical restrictions.

\section{Declarations}

\section{Competing interests}

The researcher declares no potential conflicts of interest with respect to the authorship and/or potential publication of this article. The views expressed herein are those of the author and do not necessarily reflect the views of the United Nations.

Received: 5 June 2020 Accepted: 26 April 2021

Published online: 21 June 2021

\section{References}

Ager A, Pasha E, Yu G, Duke T, Eriksson C, Cardozo BL (2012) Stress, mental health, and burnout in national humanitarian aid workers in Gulu, Northern Uganda. J Trauma Stress 25(6):713-720. https://doi.org/10.1002/jts.21764

ALNAP (2010). The State of the Humanitarian System. Assessing performance and progress. A pilot study. Retrieved 2 July 2018 from https://web.archive.org/ web/20101214081952/http://www.alnap.org/pool/files/alnap-sohs-final.pdf

Ano GG, Vasconcelles EB (2005) Religious coping and psychological adjustment to stress: a meta-analysis. J Clin Psychol 61(4):461-480. https://doi.org/10.1 002/jclp.20049

Antares Foundation (2012). Managing stress in humanitarian workers - guidelines for good practice ( $3^{\text {rd }}$ ed). Retrieved 19 May 2018 from https://www.anta resfoundation.org
Armagan E, Engindeniz Z, Devay A, Erdur B, Ozcakir A (2006) Frequency of posttraumatic stress disorder among relief force workers after the tsunami in Asia: Do rescuers become victims? Prehosp Disaster Med 21(3):168-172. https://doi.org/10.1017/S1049023X00003630

Bakker AB, Costa PL (2014) Chronic job burnout and daily functioning: a theoretical analysis. Burn Res 1(3):112-119. https://doi.org/10.1016/j.burn.2 014.04 .003

Barron RA (1999) Psychological trauma and relief workers. In: Leaning J, Briggs SM, Chen LC (eds) Humanitarian Crises: The Medical and Public Health Responses. Harvard University Press, Cambridge, pp 143-175

Baumeister RF (2012) Need-to-belong theory. In: Van Lange PAM, Kruglanski AW, Higgins ET (eds) Handbook of theories of social psychology: Volume 2. Sage Publications Ltd., Thousand Oaks, pp 121-140. https://doi.org/10.4135/ 9781446249222.n32

Bjerneld M, Lindmark G, Diskett P, Garrett MJ (2004) Perceptions of work in humanitarian assistance: interviews with returning Swedish health professionals. Disaster Manag Response 2(4):101-108. https://doi.org/10.1016/ j.dmr.2004.08.009

Bond FW, Bunce D (2003) The role of acceptance and job control in mental health, job satisfaction, and work performance. J Appl Psychol 88(6):10571068. https://doi.org/10.1037/0021-9010.88.6.1057

Bond FW, Hayes SC (2002) ACT at work. In: Bond FW, Dryden W (eds) Handbook of Brief Cognitive Behaviour Therapy. Wiley, Chichester, pp 117-139. https:// doi.org/10.1002/9780470713020

Braun V, Clarke V (2006) Using thematic analysis in psychology. Qual Res Psychol 3(2):77-101. https://doi.org/10.1191/1478088706qp063oa

Braun V, Clarke V (2013) Successful qualitative research: a practical guide for beginners. SAGE, London

British Psychological Society (2018) Code of ethics and conduct. Author, Leicester Bryant R (2006) Acute stress disorder. Psychiatry 5(7):238-239. https://doi.org/10.1 053/j.mppsy.2006.04.003

Cardozo BL, Crawford CG, Eriksson C, Zhu J, Sabin M, Ager A et al (2012) Psychological distress, depression, anxiety, and burnout among international humanitarian aid workers: a longitudinal study. 7(9):e44948. https://doi.org/1 0.1371/journal.pone.0044948 Public Library of Science One

Cardozo BL, Holtz TH, Kaiser R, Gotway CA, Ghitis F, Toomey E, Salama P (2005) The mental health of expatriate and Kosovar Albanian humanitarian aid workers. Disasters 29(2):152-170. https://doi.org/1 0.1111/j.0361-3666.2005.00278.x

Cardozo BL, Salama P (2002) Mental health of humanitarian aid workers in complex emergencies. In: Danieli Y (ed) Sharing the front line and the back hills: Peacekeepers, humanitarian aid workers and the media in the midst of crisis. Baywood Publishing, Amityville, pp 242-255

Cardozo BL, Sivilli TI, Crawford C, Scholte WF, Petit P, Ghitis F et al (2013) Factors affecting mental health of local staff working in the Vanni region, Sri Lanka. Psychol Trauma 5(6):581-590. https://doi.org/10.1037/a0030969

Chan CS, Rhodes JE (2013) Religious coping, posttraumatic stress, psychological distress, and posttraumatic growth among female survivors four years after Hurricane Katrina. J Trauma Stress 26(2):257-265. https://doi.org/10.1002/ jts.21801

Comoretto A, Crichton N, Albery I (2015) Resilience in humanitarian aid workers: understanding processes of development. IIE Transact Occup Ergonom Hum Factors 3(3-4):197-209. https://doi.org/10.1080/21577323.2015.1093565

Connor KM, Davidson JRT, Lee LC (2003) Spirituality, resilience, and anger in survivors of violent trauma: a community survey. J Trauma Stress 16(5):487494. https://doi.org/10.1023/A:1025762512279

Connorton E, Perry MJ, Hemenway D, Miller M (2011) Humanitarian relief workers and trauma-related mental illness. Epidemiol Rev 34(1):145-155. https://doi. org/10.1093/epirev/mxr026

Creta A (2018) Implementation of the duty of care by the United Nations. In: de Guttry A, Frulli M, Greppi E, Macchi C (eds) The Duty of Care of International Organizations Towards Their Civilian Personnel. T.M.C. Asser Press, The Hague, pp 167-208. https://doi.org/10.1007/978-94-6265-258-3_7

Currier JM, Eriksson CB (2017) Trauma and spirituality: empirical advances in an understudied area of community experience. J Prev Interv Commun 45(4): 231-237. https://doi.org/10.1080/10852352.2016.1197755

Dein HS, Cook HCC, Koenig HG (2012) Religion, spirituality, and mental health: current controversies and future directions. J Nerv Ment Dis 200(10):852-855. https://doi.org/10.1097/NMD.0b013e31826b6dle

Delaney HD, Miller WR, Bisonó AM (2007) Religiosity and spirituality among psychologists: a survey of clinician members of the American Psychological 
Association. Prof Psychol 38(5):538-546. https://doi.org/10.1037/0735-702 8.38.5.538

Drescher KD (2006) Spirituality in the face of terrorist disasters. In: Schein LA, Spitz HI, Burlingame GM, Muskin PR (eds) Psychological effects of catastrophic disasters: Group approaches to treatment. The Haworth Press, New York, pp 335-381

Edwards, S. (2017). Sexual assault and harassment in the aid sector: survivor stories. Washington, D.C: Devex. Retrieved 8 August 2018 from https://www. devex.com/news/sexual-assault-and-harassment-in-the-aid-sector-survivorstories-89429

Ehrenreich JH, Elliot TL (2004) Managing stress in humanitarian aid workers: a survey of humanitarian aid agencies' psychosocial training and support of staff. Peace Confl 10(1):53-66. https://doi.org/10.1207/s15327949pac1001_4

Ellison C (1998) Introduction to symposium: religion, health, and well-being. J Sci Study Relig 37(4):692-694 Retrieved from http://www.jstor.org.ezproxy.is.ed.a c.uk/stable/1388150

Ellison C, Bradshaw M, Flannelly KJ, Galek KC (2014) Prayer, attachment to God, and symptoms of anxiety-related disorders among U.S. adults. Sociol Relig 75(2):208-233. https://doi.org/10.1093/socrel/srt079

Ellison C, Fan D (2008) Daily spiritual experiences and psychological well-being among US adults. Int Interdisciplinary J Qual Life Measure 88(2):247-271. https://doi.org/10.1007/s11205-007-9187-2

Eriksson CB, Bjorck JP, Larson LC, Walling SM, Trice GA, Fawcett J, Abernethy AD, Foy DW (2009) Social support, organisational support, and religious support in relation to burnout in expatriate humanitarian aid workers. Ment Health Relig Cult 12(7):671-686. https://doi.org/10.1080/13674 670903029146

Eriksson CB, Cardozo BL, Foy DW, Sabin M, Ager A, Snider L et al (2013a) Predeployment mental health and trauma exposure of expatriate humanitarian aid workers: Risk and resilience factors. Traumatology 19(1):4148. https://doi.org/10.1177/1534765612441978

Eriksson CB, Cardozo BL, Ghitis F, Sabin M, Gotway Crawford C, Zhu J et al (2013b) Factors associated with adverse mental health outcomes in locally recruited aid workers assisting Iraqi refugees in Jordan. J Aggress Maltreat Trauma 22(6):660-680. https://doi.org/10.1080/10926771.2013.803506

Eriksson CB, Holland JM, Currier JM, Snider LM, Ager AK, Kaiser RE, Simon WS (2015) Trajectories of spiritual change among expatriate humanitarian aid workers: a prospective longitudinal study. Psychol Relig Spiritual 7(1):13-23. https://doi.org/10.1037/a0037703

Figley CR (1995) Compassion fatigue: coping with secondary traumatic stress disorder in those who treat the traumatized. Routledge, New York

Fitchett G, Rybarczyk BD, DeMarco GA, Nicholas JJ (1999) The role of religion in medical rehabilitation outcomes: a longitudinal study. Rehabil Psychol 44(4): 333-353. https://doi.org/10.1037/0090-5550.44.4.333

Garton S, Copland F (2010) 'I like this interview; I get cakes and cats!': the effect of prior relationships on interview talk. Qual Res 10(5):533-551. https://doi. org/10.1177/1468794110375231

Hackney CH, Sanders GS (2003) Religiosity and mental health: a meta-analysis of recent studies. J Sci Study Relig 42(1):43-55. https://doi.org/10.1111/14685906.t01-1-00160

Hayes SC (2004) Acceptance and commitment therapy, relational frame theory, and the third wave of behavioral and cognitive therapies. Behav Ther 35(4): 639-665. https://doi.org/10.1016/S0005-7894(04)80013-3

Hayes SC, Barnes-Holmes D, Roche B (2001) Relational frame theory: a postSkinnerian account of human language and cognition. Kluwer Academic/ Plenum, New York. https://doi.org/10.1007/b108413

Hayes SC, Luoma JB, Bond FW, Masuda A, Lillis J (2006) Acceptance and commitment therapy: model, processes and outcomes. Behav Res Ther 44(1): 1-25. https://doi.org/10.1016/j.brat.2005.06.006

Hayes SC, Strosahl KD, Wilson KG (1999) Acceptance and commitment therapy: an experiential approach to behavior change. Guildford Press, New York

Hayes SC, Wilson KG, Gifford EV, Follette VM, Strosahl K (1996) Experiential avoidance and behavioral disorders: a functional dimensional approach to diagnosis and treatment. J Consult Clin Psychol 64(6):1152-1168. https://doi. org/10.1037/0022-006X.64.6.1152

Hill PC, Pargament KI (2003) Advances in the conceptualization and measurement of religion and spirituality: implications for physical and mental health research. Am Psychol 58(1):64-74. https://doi.org/10.1037/0003-066X.58.1.64

Holtz TH, Salama P, Cardozo BL, Gotway CA (2002) Mental health status of human rights workers, Kosovo, June 2000. J Trauma Stress 15(5):389-395. https://doi.org/10.1023/A:1020133308188
Hourani LL, Williams J, Forman-Hoffman V, Lane ME, Weimer B, Bray RM (2012) Influence of spirituality on depression, posttraumatic stress disorder, and suicidality in active duty military personnel. Depress Res Treat 2012:259-267. https://doi.org/10.1155/2012/425463

Humanitarian Outcomes (2017). Behind the attacks: a look at the perpetrators of violence against aid workers. Aid Worker Security Database. Retrieved 2 July 2018 from https://aidworkersecurity.org/reports

Humanitarian Outcomes (2018). Aid Worker Security Report 2018: figures at a glance. Retrieved 30 January 2019 from https://aidworkersecurity.org/reports

IASC - Inter-Agency Standing Committee (2007). IASC guidelines on mental health and psychosocial support in emergency settings. Retrieved 29 May 2018 from https://interagencystandingcommittee.org/mental-health-and-psychosocialsupport-emergency-settings-0/content/iasc-guidelines-mental-health

IASC - Inter-Agency Standing Committee Reference Group Mental Health and Psychosocial Support in Emergency Settings (2018). A faith-sensitive approach in humanitarian response. Guidance on mental health and psychosocial programming. Retrieved 6 July 2018 from https://interagencysta ndingcommittee.org/mental-health-and-psychosocial-support-emergencysettings/documents-public/faith-sensitive-approach

Jackson A, Zyck SA. (2017). Presence and Proximity - To Stay and Deliver, Five Years On. Independent study commissioned by OCHA, the Norwegian Refugee Council, and the Jindal School of International Affairs. Retrieved 18 February from https://www.unocha.org/sites/unocha/files/Presence\%20a nd\%20Proximity.pdf.

Johnson, J. W. (2001). Support, coping, and religion: factors influencing adjustment to workplace stress amongst international relief and development personnel (Order No. 3007647). ProQuest Dissertations \& Theses Global. (304740544). Retrieved 29 June 2018 from https://search. proquest.com/docview/304740544? accountid $=10673$

King JE, Crowther MR (2004) The measurement of religiosity and spirituality: examples and issues from psychology. J Organ Chang Manag 17(1):83-101. https://doi.org/10.1108/09534810410511314

Kirkpatrick LA, Shillito DJ, Kellas SL (1999) Loneliness, social support, and perceived relationships with God. J Soc Pers Relat 16(4):513-522. https://doi. org/10.1177/0265407599164006

Koenig HG (2001) Religion and medicine II: religion, mental health, and related behaviors. Int J Psychiatry Med 31(1):97-109. https://doi.org/10.2190/BK1B-1 8TR-X1NN-36GG

Koenig HG, Hays JC, Larson DB, George LK, Cohen HJ, McCullough ME, Meador KG, Blazer DG (1999) Does religious attendance prolong survival? A six-year follow-up study of 3,968 older adults. J Gerontol A Biomed Sci Med Sci 54(7): 370-376. https://doi.org/10.1093/gerona/54.7.M370

Koenig HG, Pargament Kl, Nielsen J (1998) Religious coping and health status in medically ill hospitalized older adults. J Nerv Ment Dis 186(9):513-521. https://doi.org/10.1097/00005053-199809000-00001

Konterra Group (2017). The essential principles of staff care. Retrieved 26 May 2018 from http://www.konterragroup.net/essential-principles-staff-care-newresource/

Kvande MN, Reidunsdatter RJ, Løhre A, Nielsen ME, Espnes GA (2015) Religiousness and social support: a study in secular Norway. Rev Relig Res 57(1):87-109. https://doi.org/10.1007/s13644-014-0171-4

Lazard L, McAvoy J (2017) Doing reflexivity in psychological research: What's the point? What's the practice? Qual Res Psychol 17(2):1-19. https://doi.org/10.1 080/14780887.2017.1400144

Maltby J, Lewis C, Day L (1999) Religious orientation and psychological wellbeing: the role of the frequency of personal prayer. Br J Health Psychol 4(4): 363-378. https://doi.org/10.1348/135910799168704

Mao X, Fung OWM, Hu X, Loke AY (2018) Psychological impacts of disaster on rescue workers: a review of the literature. Int J Disaster Risk Reduct 27:602617. https://doi.org/10.1016/j.ijdrr.2017.10.020

Maslach C, Jackson SE (1981) The measurement of experienced burnout. J Organ Behav 2(2):99-113. https://doi.org/10.1002/job.4030020205

McCall M, Salama P (1999) Training and support of relief workers: an occupational health issue. Br Med J 318(7176):113-116. https://doi.org/10.113 6/bmj.318.7176.113

McCormack L, Joseph S (2013) Psychological growth in humanitarian aid personnel: reintegrating with family and community following exposure to war and genocide. Community Work Fam 16(2):147-163. https://doi.org/10.1 080/13668803.2012.735478

McKay, L. (2010). Spirituality and humanitarian work: maintaining your vitality. California, Pasadena: The Headington Institute. Retrieved 24 April 2018 from 
http://headington-institute.org/topic-areas/123/resilience/129/spirituality-mea ning-and-purpose

McLean C, Follette VM (2016) Acceptance and commitment therapy as a nonpathologizing intervention approach for survivors of trauma. J Trauma Dissociation 17(2):138-150. https://doi.org/10.1080/15299732.2016.1103111

Moreira-Almeida A, Koenig HG, Lucchetti G (2014) Clinical implications of spirituality to mental health: review of evidence and practical guidelines. Rev Bras Psiquiatr 36(2):176-182. https://doi.org/10.1590/1516-4446-2013-1255

Musa SA, Hamid A (2008) Psychological problems among aid workers operating in Darfur. Soc Behav Personal 36(3):407-416. https://doi.org/10.2224/sbp.2 008.36.3.407

Nicholson A, Rose R, Bobak M (2009) Association between attendance at religious services and self-reported health in 22 European countries. Soc Sci Med 69(4):519-528. https://doi.org/10.1016/j.socscimed.2009.06.024

OCHA - UN Office for the Coordination of Humanitarian Affairs (2011). To stay and deliver. Good practice for humanitarians in complex security environments. Retrieved 18 February from https://www.refworld.org/docid/4 d9039e32.html

Pargament KI (2012) Religion and coping: the current state of knowledge. In: Folkman S (ed) The Oxford Handbook of Stress, Health, and Coping. Oxford University Press. https://doi.org/10.1093/oxfordhb/9780195375343.013.0014

Pargament KI, Ishler K, Dubow EF, Stanik P, Rouiller R, Crowe P et al (1994) Methods of religious coping with the Gulf War: cross-sectional and longitudinal analyses. J Sci Study Relig 4(33):347-361. https://doi.org/10.23 $07 / 1386494$

Pargament Kl, Koenig HG, Tarakeshwar N, Hahn J (2001) Religious struggle as a predictor of mortality among medically ill elderly patients: a 2-year longitudinal study. Arch Intern Med 161(15):1881-1885. https://doi.org/10.1 $001 /$ archinte.161.15.1881

Pargament Kl, Smith BW, Koenig HG, Perez L (1998) Patterns of positive and negative religious coping with major life stressors. J Sci Study Relig 37(4): 710-724. https://doi.org/10.2307/1388152

Park CL (2017) Spiritual well-being after trauma: correlates with appraisals, coping, and psychological adjustment. J Prev Interv Commun 45(4):297-307. https://doi.org/10.1080/10852352.2016.1197752

Peres JF, Moreira-Almeida A, Nasello AG, Koenig HG (2007) Spirituality and resilience in trauma victims. J Relig Health 46(3):343-350. https://doi.org/10.1 007/s10943-006-9103-0

Pew Research Centre (2015). Religious composition by country, 2010-2050. Retrieved 20 December 2017 from http://www.pewforum.org/2015/04/02/ religious-projection-table/2010/percent/all/

Purvanova RK, Muros JP (2010) Gender differences in burnout: a meta-analysis. J Vocat Behav 77(2):168-185. https://doi.org/10.1016/j.jvb.2010.04.006

Putman KM, Lantz Jl, Townsend CL, Gallegos AM, Potts AA, Roberts RC, Cree ER, de Villagrán M, Eriksson CB, Foy DW (2009) Exposure to violence, support needs, adjustment, and motivators among Guatemalan humanitarian aid workers. Am J Community Psychol 44(1-2):109-115. https://doi.org/10.1007/ s10464-009-9249-5

Pyett PM (2003) Validation of qualitative research in the "real world". Qual Health Res 13(8):1170-1179. https://doi.org/10.1177/1049732303255686

Ritchie J, Lewis J, Elam G (2003) Designing and selecting samples. In: Ritchie J, Lewis J (eds) Qualitative Research Practice. A Guide for Social Science Students and Researchers. Sage Publications, London, pp 77-108

Schafer A (2010) Spirituality and mental health in humanitarian contexts: an exploration based on World Vision's Haiti earthquake response. Intervention 8(2):121-130. https://doi.org/10.1097/WTF.0b013e32833c1f57

Selby SP, Braunack-Mayer A, Moulding N, Jones A, Clark S, Beilby J (2009) Resilience in re-entering missionaries: Why do some do well? Ment Health Relig Cult 12(7):701-720. https://doi.org/10.1080/13674670903131868

Seybold KS, Hill PC (2001) The role of religion and spirituality in mental and physical health. Curr Dir Psychol Sci 10(1):21-24. https://doi.org/10.1111/14 67-8721.00106

Shaw A, Joseph S, Linley PA (2005) Religion, spirituality, and posttraumatic growth: a systematic review. Ment Health Relig Cult 8(1):1-11. https://doi. org/10.1080/1367467032000157981

Sheik M, Gutierrez MI, Bolton P, Spiegel P, Thieren M, Burnham G (2000) Deaths among humanitarian workers. Br Med J 321(7254):166-168. https://doi.org/1 $0.1136 /$ bmj.321.7254.166

Silverman D (2000) Doing qualitative research: a practical guide. Sage Publications, Thousand Oaks
Smigelsky MA, Gill AR, Foshager D, Aten JD, Im H (2017) "My heart is in his hands": the lived spiritual experiences of Congolese refugee women survivors of sexual violence. J Prev Interv Commun 45(4):261-273. https://doi. org/10.1080/10852352.2016.1197754

Smith JA (1995) Semi-structured interviewing and qualitative analysis. In: Smith JA, Harré R, van Langenhove L (eds) Rethinking Methods in Psychology. Sage, London, pp 9-26. https://doi.org/10.4135/9781446221792.n2

Smith S (2004) Exploring the interaction of trauma and spirituality. Traumatology 10(4):231-243. https://doi.org/10.1177/153476560401000403

Stoddard A, Harmer A, DiDomenico V (2009) Providing aid in insecure environments: 2009 update. (The Humanitarian Policy Brief 34). Center for International Cooperation at New York University, New York

Ten years ago I was sent to DR Congo as an aid worker without security training. Not much has changed (2017). New York: Quartz Africa. Retrieved 7 July 2018 from https://qz.com/995889/un-and-ngo-aid-workers-need-better-tra ining-in-countries-like-dr-congo/

Terry G, Hayfield N, Clarke V, Braun V (2017) Thematic analysis. In: Willig C, Rogers W (eds) The SAGE Handbook of Qualitative Research in Psychology. London: SAGE Publications

Tix AP, Frazier PA (1998) The use of religious coping during stressful life events: main effects, moderation, and mediation. J Consult Clin Psychol 66(2):411422. https://doi.org/10.1037/0022-006X.66.2.411

Trippany RL, Kress VEW, Wilcoxon SA (2004) Preventing vicarious trauma: what counselors should know when working with trauma survivors. J Couns Dev 82(1):31-37. https://doi.org/10.1002/j.1556-6678.2004.tb00283.x

UNGA - United Nations General Assembly (1948). Preparations for injuries incurred in the service of the United Nations [1948] UNGA 47; A/RES/258 (III) (3 December 1948). Retrieved 21 February 2021 from http://www.worldlii. org/int/other/UNGA/1948/

UNS - United Nations System, Chief Executive Board for Coordination, High-Level Committee on Management (2018). Cross-functional task force on duty of care for personnel in high risk environment report, April 2018. Retrieved 8 July 2018 from https://www.unsystem.org/content/•-hlcm-35th-session-april-2 018-report-cross-functional-task-force-duty-care

Vasileiou K, Barnett J, Thorpe S, Young T (2018) Characterising and justifying sample size sufficiency in interview-based studies: systematic analysis of qualitative health research over a 15-year period. BMC Med Res Methodol 18(1):1-18

Wartenweiler T, Eiroa-Orosa FJ (2016) Effects of spiritual change on the re-entry adjustment of Christian young adult humanitarian workers. J Pastoral Care Counsel 70(3):176-185. https://doi.org/10.1177/1542305016655177

Welton-Mitchell, C.E. (2013). UNHCR's mental health and psychosocial support for staff. Geneva: UNHCR. Retrieved 6 July 2018 from http://www.unhcr.org/51 f67bdc9.pdf

World Health Organization (2011). Psychological first aid: guide for field workers. Retrieved 6 July 2018 from http://www.who.int/mental_health/publications/ guide_field_workers/en/

Young, Holly (2015). Guardian research suggests mental health crisis among aid workers. London: The Guardian. Retrieved 9 July 2018 from https://www. theguardian.com/global-development-professionals-network/2015/nov/23/ guardian-research-suggests-mental-health-crisis-among-aid-workers

\section{Publisher's Note}

Springer Nature remains neutral with regard to jurisdictional claims in published maps and institutional affiliations. 